\title{
Seminario-Taller «Lenguas indígenas y comunicación transcultural en América Colonial»
} Lima, 9 de agosto de 2014

\section{César Itier}

\section{(2) OpenEdition}

\section{Journals}

Edición electrónica

URL: http://journals.openedition.org/bifea/5308

DOI: 10.4000/bifea.5308

ISSN: 2076-5827

\section{Editor}

Institut Français d'Études Andines

\section{Edición impresa}

Fecha de publicación: 1 agosto 2014

Paginación: 405-407

ISSN: 0303-7495

\section{Referencia electrónica}

César Itier, « Seminario-Taller «Lenguas indígenas y comunicación transcultural en América

Colonial» », Bulletin de l'Institut français d'études andines [En línea], 43 (2) | 2014, Publicado el 08 agosto 2014, consultado el 06 noviembre 2020. URL : http://journals.openedition.org/bifea/5308 ; DOI : https://doi.org/10.4000/bifea.5308

Les contenus du Bulletin de l'Institut français d'études andines sont mis à disposition selon les termes de la licence Creative Commons Attribution - Pas d'Utilisation Commerciale - Pas de Modification 4.0 International. 


\section{SEMINARIO-TALLER «LENGUASINDÍGENASYCOMUNICACIÓNTRANSCULTURAL EN AMÉRICA COLONIAL»}

Lima, 9 de agosto de 2014

Organizado por Juan Carlos Estenssoro y César Itier con el auspicio del Instituto Francés de Estudios Andinos (IFEA), la Agence Nationale de la Recherche, el Centre de Recherche et de Documentation des Amériques (CREDA) y el Centre de Recherche sur l'Amérique Espagnole Coloniale (CRAEC) — dos centros de investigación de la Universidad de la Sorbona Nueva (París III)—, este seminariotaller tuvo lugar en el Museo de Arqueología, Antropología e Historia (Lima) el día sábado 9 de agosto del 2014. Fue animado por miembros del proyecto de investigación «Lenguas Generales de América del Sur (quechua, aimara, guaraní, tupí, siglos XVI-XIX)» (LANGAS), dedicado al estudio de las lenguas indígenas que alcanzaron una gran difusión en la época colonial y gozan de una abundante documentación. Esta jornada estuvo dirigida, por una parte, a estudiantes y colegas de historia, lingüística y literatura, siendo su objetivo iniciar a los participantes a la filología de las lenguas indígenas. Dado que la investigación filológica también enseña a ver la profundidad histórica yacente pero activa en la cultura y la lengua actuales, este seminario-taller estuvo dirigido igualmente a antropólogos como a quechuahablantes que escriben en su lengua y están interesados por conocer el recorrido histórico de su idioma y dominar los recursos patrimoniales del mismo. Alrededor de 30 participantes asistieron a esta jornada. Aproximadamente un tercio de ellos era quechuahablante, otro tercio había estudiado el quechua a un nivel básico o avanzado y el tercio restante no tenía conocimiento de la lengua. De la misma manera, alrededor de un tercio de los participantes eran historiadores, un tercio especialistas en literatura y otro tercio eran lingüistas o antropólogos.

En su vertiente andina, el proyecto LANGAS partió de la observación de lo poco que se ha avanzado en la comprensión de las sociedades indígenas de las 
épocas inca y colonial desde su propia institucionalidad. Desde el año 1960, la etnohistoria andina se ha desarrollado a partir de la constatación de la dificultad que tienen los historiadores en entender las sociedades indígenas a través de fuentes redactadas por el colonizador y en español. Dicha disciplina ha tratado de definirse por la búsqueda de los ecos de las concepciones indígenas en la documentación hispana. Paradójicamente, sin embargo, ha desatendido casi por completo la rica documentación producida en quechua y aimara a lo largo de la época colonial y, pese a los trabajos fundadores de Gerald Taylor, la filología de las lenguas andinas se encuentra todavía en ciernes. Este seminario-taller trató de mostrar las posibilidades de renovación historiográfica y epistemológica que encierra el estudio de la considerable documentación escrita en estas lenguas. Se cree, en efecto, que la filología de las lenguas indígenas puede contribuir a vertebrar la investigación histórica sobre el pasado indígena y que el análisis de las fuentes en dichas lenguas abre posibilidades inéditas de comprensión de las sociedades indígenas en sus propios términos.

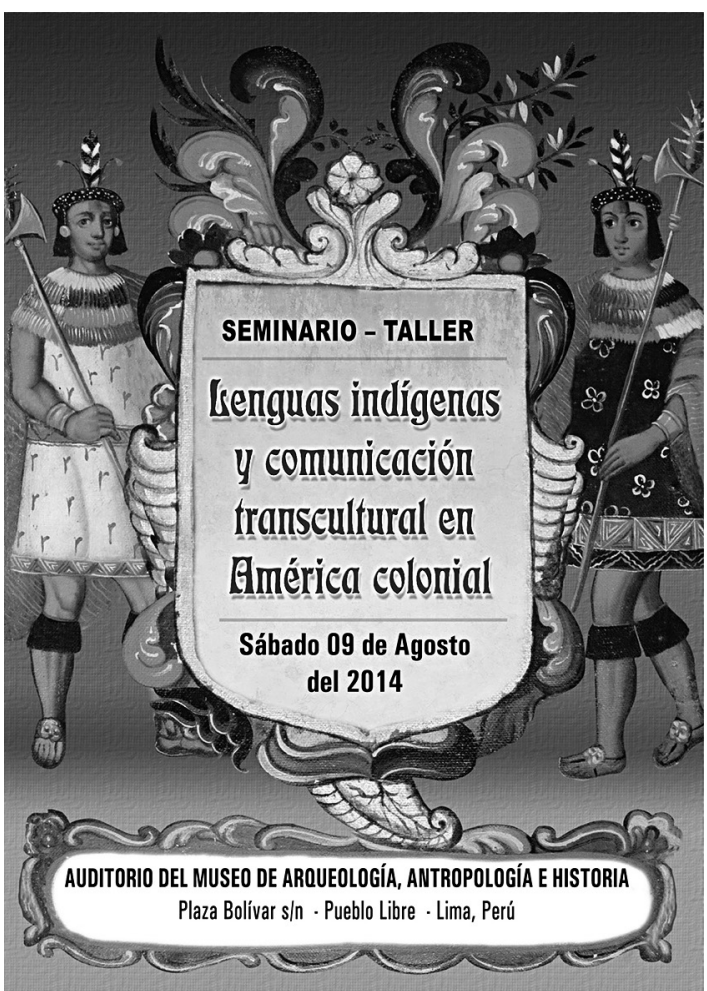

La mañana y el inicio de la tarde estuvieron dedicados a tres exposiciones generales a cargo de los miembros del proyecto LANGAS, las cuales fueron sometidas a discusión por los asistentes. César Itier, filólogo y profesor de quechua en el Instituto Nacional de Lenguas y Civilizaciones Orientales (París), presentó el corpus quechua colonial, su contexto sociolingüístico de producción y las posibilidades de desarrollar una historia social de las lenguas en el Perú colonial. El historiador Juan Carlos Estenssoro (Universidad de la Sorbona Nueva, París) puso de manifiesto el impacto que la cristianización tuvo tanto sobre la ecología de las lenguas andinas como sobre algunos campos de su léxico (por ejemplo, el del baile y el canto). El objetivo de estas dos conferencias fue sacar a la luz los principales procesos que intervinieron en la dinámica interna y externa de las «lenguas generales» andinas en la época colonial y los factores que condicionaron la forma específica que tomó su gramatización y «literización». Se cree, en efecto, que la historia de dichos idiomas, hasta ahora casi exclusivamente estudiada por lingüistas, adolece de una percepción «inmovilista», que no toma en consideración los profundos cambios que la colonización indujo en la configuración geográfica de su variación dialectal así como en su misma estructura semántica. Nos pareció fundamental transmitir a los asistentes la conciencia de la 
profundidad histórica de las lenguas indígenas, de los cambios internos y externos que las afectaron en los últimos siglos y de las posibilidades de investigarlos. La tercera exposición de la parte seminario de esta jornada fue la de Capucine Boidin, antropóloga del Instituto de Altos Estudios sobre América Latina (IHEAL, París) y especialista del Paraguay y de la lengua guaraní. En contrapunto a las exposiciones anteriores, presentó primero la documentación colonial en esta lengua. Se esbozó una comparación entre los corpus en lenguas indígenas quechua-aimara y guaraní, los cuales se diferencian uno de otro de manera profunda y significativa. Luego, Capucine Boidin presentó algunos instrumentos metodológicos para el estudio histórico del vocabulario indígena.

En el taller de la tarde se presentó la base de datos en línea del proyecto LANGAS ${ }^{1}$, creada para facilitar el acceso a los corpus históricos de las «lenguas generales» y ayudar a la investigación filológica. La parte quechua de esta base de datos comprende ya alrededor de 3000 páginas de textos y diccionarios bilingües quechua-español producidos entre fines del siglo XVI e inicios del XIX. Gracias al constante aporte de los miembros del proyecto LANGAS y de algunos colaboradores, esta base se encuentra en rápido crecimiento. Un motor de búsqueda y un generador de grafías permite buscar en el corpus lexemas, palabras y combinaciones morfológicas quechuas y acceder directamente a sus contextos de uso y equivalencias en español. La búsqueda en el corpus también se puede hacer a partir de palabras en castellano. Lo mismo se puede llevar a cabo con el corpus guaraní y se prevé incluir en la base textos en aimara y tupí.

Para una primera demostración se partió de las frases iniciales del capítulo 5 del Manuscrito de Huarochirí, un documento en el cual los contextos de empleo del vocabulario son, por razones obvias, especialmente ricos. Se buscó dos elementos clave del vocabulario de este pasaje (qapaq 'rico' y wakcha 'pobre') en otros documentos quechuas de la época colonial. En efecto, entender un texto producido por una cultura distante implica en primer lugar entender los conceptos que lo vertebran, los cuales se aclaran - para nosotros - por sus empleos en otros documentos de la misma época. Se trata, por lo tanto, de acercarnos a una definición de dichos conceptos tales como existían en la época, contrastándola con la que tienen hoy en día. Se intentó mostrar así la fecundidad de investigaciones que combinen la historia semántica con el estudio de la literatura escrita antigua y oral actual. Finalmente, los asistentes formularon sus propias preguntas a la base de datos y esbozamos una serie de búsquedas y una discusión sobre los métodos del análisis semántico. 